\title{
Local delivery of bisphosphonate from coated orthopedic implants increases implants mechanical stability in osteoporotic rats
}

\author{
Bastian Peter, ${ }_{1}^{1}$ Olivier Gauthier, ${ }^{2}$ Samia Laïb, ${ }^{3}$ Bruno Bujoli, ${ }^{3}$ Jérôme Guicheux, ${ }^{2}$ Pascal Janvier, ${ }^{3}$ \\ G. Harry van Lenthe, ${ }^{4}$ Ralph Müller, ${ }^{4}$ Pierre-Yves Zambelli, ${ }^{5}$ Jean-Michel Bouler, ${ }^{2}$ Dominique P. Pioletti ${ }^{1}$ \\ ${ }^{1}$ Bone Bioengineering Group, Laboratory of Orthopedic Research, Swiss Federal Institute of Technology Lausanne \\ (EPFL), Switzerland \\ ${ }^{2}$ Laboratoire de Recherche sur les Materiaux d'Intérêt Biologique INSERM 99-03, Faculté de Chirurgie Dentaire, \\ Nantes, France \\ ${ }^{3}$ Laboratoire de Synthèse Organique UMR CNRS 6513, Faculté des Sciences, Nantes, France \\ ${ }^{4}$ Institut for Biomedical Engineering, Swiss Federal Institute of Technology (ETH) and University of Zurich, Switzerland \\ ${ }^{5}$ Hôpital Orthopédique de la Suisse Romande, Lausanne, Switzerland
}

Received 11 February 2005; revised 26 April 2005; accepted 2 May 2005

Published online 27 October 2005 in Wiley InterScience (www.interscience.wiley.com). DOI: 10.1002/jbm.a.30456

\begin{abstract}
Patients with osteoporosis and joint disabilities represent a constant growing and challenging population to be treated in the musculoskeletal clinical field. Especially in the case of total hip arthroplasty, new solutions should be developed to compensate for the double negative factors, peri-implant osteolysis, and osteoporotic bone loss, affecting the quality of implant outcome. The goal of this study was then to establish a proof of concept for orthopedic implant used as Zoledronate delivery in osteoporotic rats, and in particular, to verify if this approach could increase the initial implant stability. Twenty-five female 6-month-old Wistar rats were ovariectomized 6 weeks before the implantation to induce osteoporosis. The animals were randomly separated in five groups representing the different Zoledronate concentrations in the HA coating: 0, 0.2, 2.1, 8.5, and $16 \mu \mathrm{g}$ /implant. Histomorphometric measures and peri-implant bone volume fraction were assessed and mechanical stability tests were performed. Bone
\end{abstract}

volume fraction and biomechanical results clearly illustrate the positive effect of Zoledronate coated implants in the osteoporotic rats. A remarkable result was to show the existence of a window of Zoledronate content ( 0.2 to $8.5 \mu \mathrm{g} /$ implant) in which the mechanical fixation of the implant increased. We were able to establish the proof of concept for orthopedic implants used as a drug delivery system in osteoporotic rats. The local bisphosphonate delivery from a calcium phosphate coating allowed increase of the mechanical fixation of an orthopedic implant. This study shows that orthopedic implants containing bisphosphonates could be beneficial for osteoporotic patients in need of a total joint replacement. (C) 2005 Wiley Periodicals, Inc. J Biomed Mater Res 76A: 133-143, 2006

Key words: osteoporosis; bisphosphonates; orthopedic implant; local delivery

\section{INTRODUCTION}

Total hip arthroplasty is the method most often preferred for treatment of osteoporotic patients with femoral neck fractures, being implanted with, or in the press-

Correspondence to: D. P. Pioletti; e-mail: dominique. pioletti@epfl.ch

Contract grant sponsor: the French Ministry of Research (ACI "Technologies pour la Santé")

Contract grant sponsor: the C.N.R.S. (Programme "Matériaux Nouveaux-Fonctionnalités Nouvelles")

Contract grant sponsor: "Fondation de l'avenir pour la recherche médicale appliquée

Contract grant sponsor: the Région Pays de la Loire (CPER "Biomatériaux-S3")

(c) 2005 Wiley Periodicals, Inc. fit technique without use of cement. ${ }^{1}$ Initially, uncemented total hip arthroplasty was often indicated for younger patients ( $<60$ years old) as revision of cemented prosthesis is very cumbersome and potentially damaging to the bone. However, the uncemented implants are also more and more used in older patients ${ }^{2}$ due to the mean life expectancy increase. Uncemented hip implants have also shown excellent results for difficult orthopedic situations such as revisions. ${ }^{3}$ This technique was motivated by the fact that poor durability of cemented fixation was observed in revision due to low bone quality. Similarly, uncemented hip implant may also be an attractive technique in osteoporotic situations. Indeed, recently it has been shown that osteoporotic bone as a factor by itself does not compromise the early results of uncemented hip implant. ${ }^{4}$ 
Long-term survival of uncemented hip components is highly dependent on biological fixation. The initial fixation of the implant is crucial for the success of the implant. 5 ,6 Osteoconductive coatings such as hydroxyapatite have been developed to increase implant fixation with various amounts of success. ${ }^{7}$ Despite several potential advantages of uncemented implants in regard to cemented ones, the clinical results are still superior for the cemented implants. ${ }^{8}$

Recently, a pharmacological approach with bisphosphonate has been tested in an animal study to increase the implant outcome. ${ }^{9}$ The basic idea was to decrease the primary failure mode, which is aseptic loosening following peri-implant osteolysis. ${ }^{10}$ Results of two different clinical studies, using a treatment of $10 \mathrm{mg}$ Alendronate daily for 6 months $^{11}$ or for 2 years ${ }^{12}$ showed a reduction of peri-implant bone loss in the treated groups. In both studies, differences became evident after 3 months. Similar results were obtained with cyclic Ethidronate therapy. ${ }^{13}$

In parallel, it has been shown that significant bone loss, up to $14 \%$, arise during the first 3 months after total hip arthroplasty. ${ }^{14}$ It would be important for initial implant stability to decrease the time delay for the bisphosphonate to reach the peri-implant bone. Systemic delivery of bisphosphonate may then not be an optimal delivery mode for the prevention of periimplant bone loss. Indeed, a local drug delivery system would seem more appropriate. This approach would allow to directly target the peri-implant bone, and would then probably increase the bisphosphonate efficiency. Indeed, recently a coated implant surface with bisphosphonate stimulated new bone formation around the implant ${ }^{15}$ and increased mechanical stability. ${ }^{16}$ The combination of hydroxyapatite (HA) coating and bisphosphonate would be especially interesting, as hydroxyapatite is widely used in orthopedic implants and bisphosphonates are known to be easily combined with HA. To this end, we have extensively characterized the combination of calcium phosphate with Zoledronate to better understand and control the release mode of this bisphosphonate. ${ }^{17,18}$

The goal of this study was then to establish a proof of concept for orthopedic implants using Zoledronate delivery in osteoporotic rats, and in particular, to verify if this approach could increase the initial implant stability.

\section{MATERIALS AND METHODS}

\section{Osteoporotic rats}

Twenty-five female 6-month-old Wistar rats were used for this experiment. The animals had free access to normal diet. The rats were ovariectomized 6 weeks before the implanta-
TABLE I

Number of Rats per Condition and Femur (Slices) per Test

\begin{tabular}{lccc}
\hline \multicolumn{1}{c}{ Conditions } & Rats & $\begin{array}{c}\text { SEM } \\
\text { Histomorphometry }\end{array}$ & $\begin{array}{c}\mu-\mathrm{CT} \text { and } \\
\text { Biomech. Tests }\end{array}$ \\
\hline Control & 5 & $5(40)$ & 4 \\
$0.2 \mu \mathrm{g} /$ implant & 5 & $5(35)$ & 4 \\
$2.1 \mu \mathrm{g} /$ implant & 5 & $3(27)$ & 3 \\
$8.5 \mu \mathrm{g} /$ implant & 5 & $5(42)$ & 4 \\
$16 \mu \mathrm{g} /$ implant & 5 & $4(39)$ & 4 \\
\hline
\end{tabular}

tion to induce osteoporosis. The animals were randomly separated into five groups representing the different Zoledronate concentrations in the HA coating: 0, 0.2, 2.1, 8.5, and 16 $\mu \mathrm{g} /$ implant (Table I). Three rats died of causes unrelated to the study. Each rat received two implants containing the same Zoledronate content, one in each femoral condyle. In each animal, one condyle was used for bone volume fraction measurement and histomorphometric measurements with SEM, while the contralateral condyle was used for $\mu-C T$ and biomechanical pullout tests.

\section{Implants and Zoledronate}

Titanium alloy (TA6V) cylinders (diameter $3 \mathrm{~mm}$; length 5 $\mathrm{mm}$ ) were plasma coated with hydroxyapatite (thickness: 20 $\mu \mathrm{m}$; cristallinity index 62\%). Zoledronate (1-hydroxy-2-[(1Himidazole-1-yl)ethylidene] 1-bisphosphonic acid disodium salt) was supplied by Novartis Pharmaceuticals AG, Basel, Switzerland.

\section{Zoledronate coating}

Calcium phosphate ceramics have been recently developed for Zoledronate delivery, and have been extensively described in previous work. ${ }^{17,18}$ In summary, the chemical association of Zoledronate with the HA coating was carried out by soaking the implants in Zoledronate solution in ultrapure water. No stirring of the reaction vessel was performed to prevent any mechanical erosion of the HA coating. Fifty implants were immersed for $48 \mathrm{~h}$ in $5 \mathrm{~mL}$ of aqueous Zoledronate solutions of various concentration: 0 , $2.2510^{-6}, 2.2510^{-5}, 2.2510^{-4}$, and $2.2510^{-3} \mathrm{~mol} \mathrm{~L}^{-1}$, leading to modified coatings. Then, the remaining amount of Zoledronate in the supernatant at the end of the reaction was determined as previously described. ${ }^{16,18}$ By difference with the initial amount of Zoledronate present in solution, the Zoledronate-loading onto the implants was deduced, namely 0 (corresponding to the control), $0.2,2.1,8.5$, and 16 $\mu \mathrm{g}$ of Zoledronate per implant. The presence of Zoledronate on the modified implants was investigated in the case of the coating loaded with $16 \mu \mathrm{g} /$ implant; for that purpose the calcium phosphate coating was removed from the implant, and a solid-state ${ }^{31} \mathrm{P}$ CP-MAS NMR spectrum of the resulting powder clearly showed a weak signal in the expected range for Zoledronate (10-20 ppm), along with the reso- 

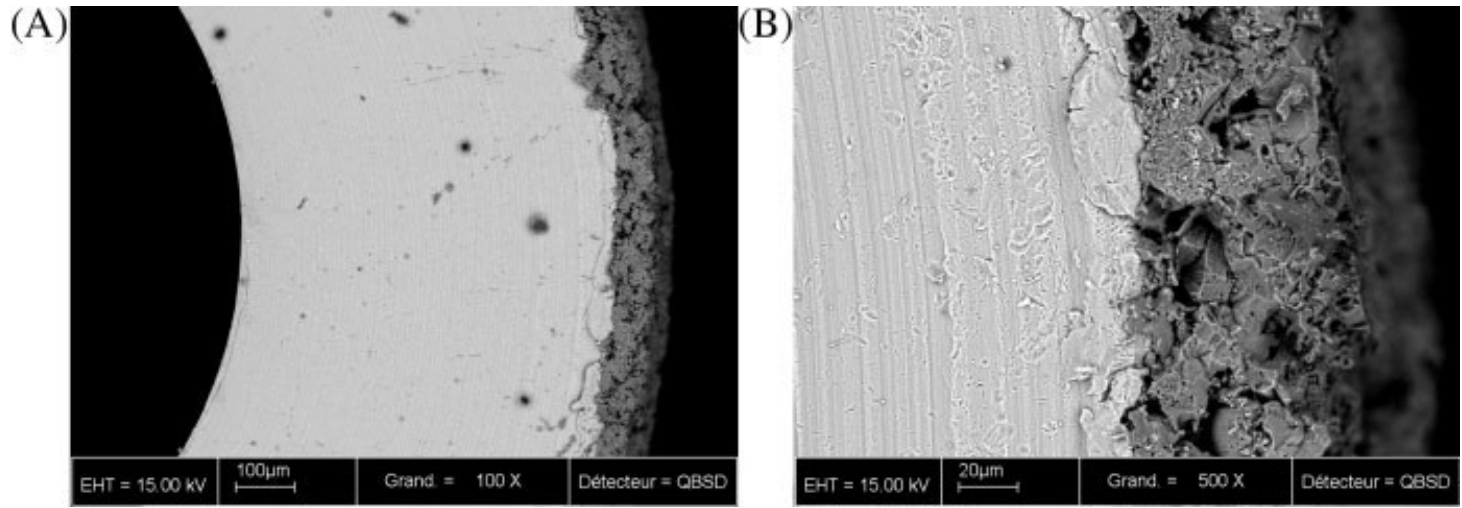

Figure 1. An implant with the HA coating (2.1 $\mu$ g Zoledronate per implant) was observed with a LEO 1450VP scanning electron microscope (LEO, Cambridge, UK). (A) Shows the thickness of the coating with respect to the titanium implant, while (B) clearly highlights the structure of the HA coating. Both SEM pictures were performed in backscattered mode.

nance corresponding to the calcium phosphate [2.7 (strong) and 6 (weak) ppm]. Using SEM, no alteration of the coating due to the grafting process could be measured (Fig. 1).

\section{In vivo implant protocol}

The protocol for the animal experiment was approved by the local Ethical Committee for Animal studies of the National Veterinary School of Nantes. Animals were kept at the Experimental Surgery Laboratory of the Nantes University according to European Community guidelines for the care and use of laboratory animals (DE86/609/ CEE). Surgical procedures were conducted under general anesthesia using intraperitoneal injection of sodium thiopental associated with subcutaneous injection of morphine sulfate. Bilateral implantations were performed at the distal end of the femurs, at the epiphyso-metaphyseal junction. After lateral arthrotomy of the knee joint, the lateral condyle was exposed and drilled perpendicularly to the long axis of the femur. The drilling procedure was performed with two successive bits $(2.2$ and $2.8 \mathrm{~mm}$ in diameter) on a low speed rotative dental handpiece and under sterile saline irrigation. Hemostasis of the bone cavity was controlled with sterile gauges and the coated implant was then gently inserted into the cavity under digital pressure. The surgeon was blinded for the Zoledronate loading of the implant. Articular and cutaneous tissues were closed in two separate layers. After surgery, all the animals were allowed to move freely in their cages. Animals were killed 3 weeks after implantation by intracardiac injection of overdosed sodium pentobarbital, after induction of intraperitoneal general anesthesia. Using the $\mu$-CT images, it was established that the position of the implants in the condyle was similar for all animals (Fig. 2).

\section{SEM}

After overdosed injection, the rats femoral ends used for SEM were immediately dissected, fixed in glutaraldehyde solution and stored in a $4 \%$ paraformaldehyde, $0.1 \%$ glutaraldehyde in $0.08 \mathrm{M}$ cacodylate buffer. Using a handpiece, the condyle was sawed off $1 \mathrm{~cm}$ above the implant. The sample was dehydrated in a series of alcohol solutions. The first impregnation step was to soak the sample in a mixture of $50 \%$ alcohol $100^{\circ}$ and 50\% methyl-methacrylate MMA
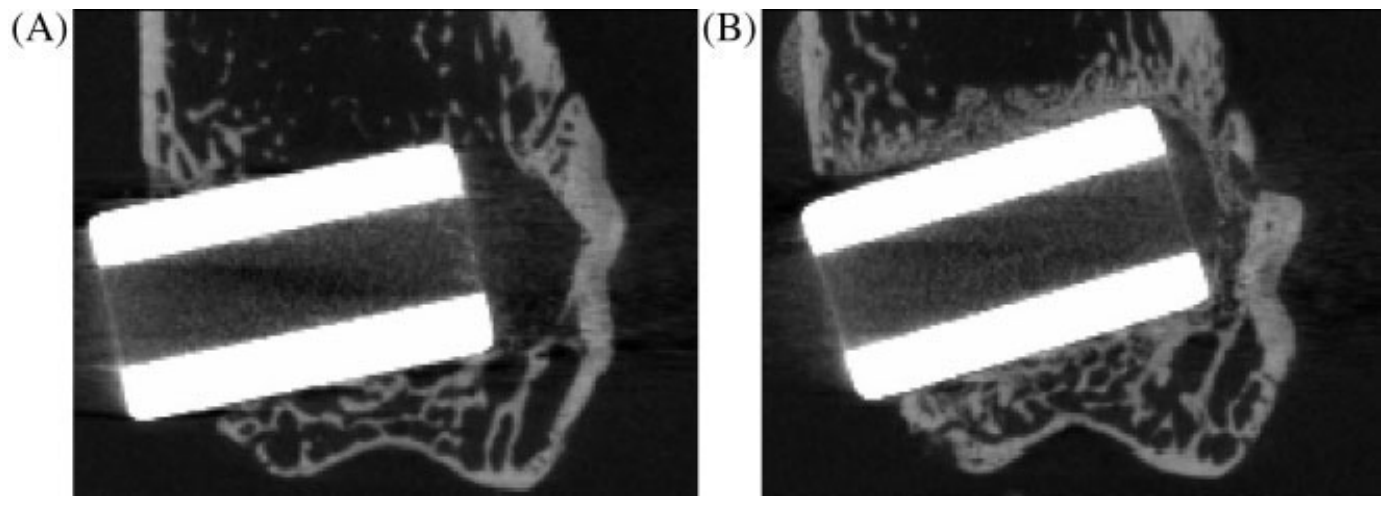

Figure 2. To check the insertion depth of the implants, $\mu$-CT measurements where performed at the end of the experiments ( 3 weeks). It was established that the insertion depth was almost the same for all the implants. Exemples of the obtained results are shown. The hollow implant is shown in white, the bone in gray (A, $0 \mu \mathrm{g} / \mathrm{implant;} \mathrm{B}, 8.5 \mu \mathrm{g} / \mathrm{implant}$ ). 

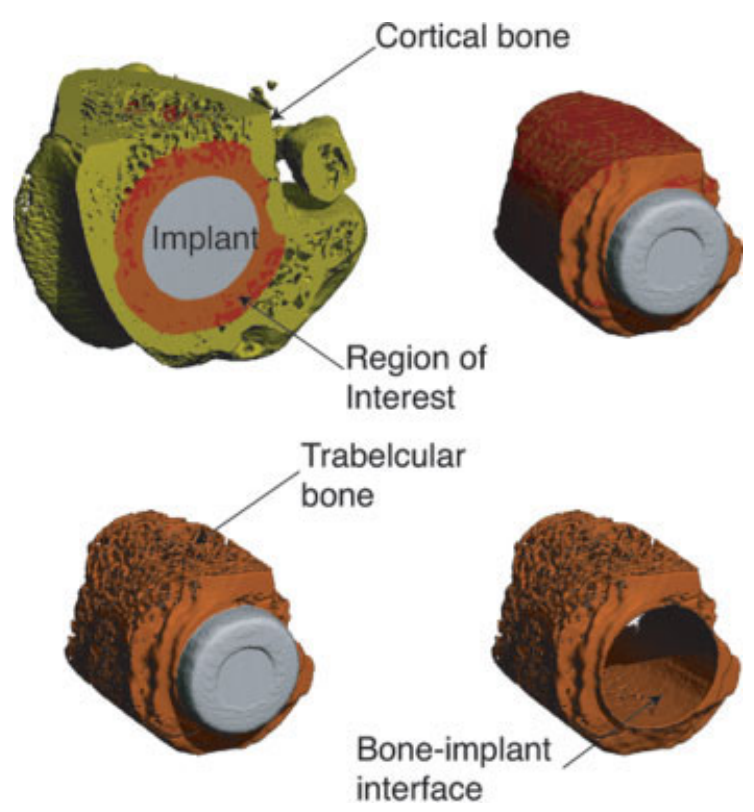

Figure 3. The data obtained with the $\mu$-CT shows a 3D view of the implanted condyles. The implant is shown in gray, the bone in yellow, and the region of interest in red. The region of interest can be numerically extracted and bone density can be quantified.

(Fluka Chemika, Sigma Aldrich Chemie Gmbh, Steinheim, Germany) for $24 \mathrm{~h}$. The second impregnation step was to soak the sample in pure MMA for $24 \mathrm{~h}$. The first inclusion step was to soak the dehydrated sample for $2 \mathrm{~h}$ under vacuum in a solution containing 90\% MMA, 10\% dibutylphtalate (Fluka Chemika), and 1\% benzoyl peroxyde (Fluka Chemika). The sample was then removed from the solution and soaked in the same solution but enhanced by a polymerization activator ( $N, N$ dimethyl- $p$-toluidine) (Fluka Chemika). The polymerization took place at $-20^{\circ} \mathrm{C}$ and was complete after $48 \mathrm{~h}$. The samples were cut in slices $100 \mu \mathrm{m}$ thick using a Microtome saw 1600 (Leica, Nussloch, Germany) diamond saw. The cutting plane was perpendicular to the implant. The slices were carbon coated, and the number of slices per animal is reported in Table I. The samples were then observed in a JEOL JSM 6300 scanning electron microscope (JEOL, Tokyo, Japan) using the backscattered electron detector allowing to distinguish mineralized bone from soft tissue. Each sample was observed at two different magnifications: $10 \times$ and $23 \times$. These two magnifications were chosen to assess the influence of the biocoating close to the implant and further away. Using Quantimet (Zeiss, Jena, Germany), the bone volume fraction and bone surface were measured as a function of the distance from the surface of the implant up to a distance of $200 \mu \mathrm{m}$ on the pictures taken at a magnification of $23 \times$. By surface of the implant it is meant the external side of the HA-coated titanium cylinder. The bone volume fraction is defined as the ratio of the white surface of the examined area divided by the total surface of the examined area.

\section{Histomorphometry}

A number of histomorphometric parameters have been measured $^{19}$ and the following parameters were influenced by the biocoating: mean length of terminus-to-terminus struts (Tm - Tm/TSL), mean length of node-to-terminus struts $(\mathrm{Nd} \cdot \mathrm{Tm} / \mathrm{TSL})$, node to termini ratio $(\mathrm{Nd} \cdot \mathrm{Tm})$, mean length of node to node struts $(\mathrm{Nd} \cdot \mathrm{Nd} / \mathrm{TSL})$, number of termini in the calcified skeleton $(\mathrm{N} \cdot \mathrm{Tm})$, total strut length (TSL). The calculations were performed using a home-written procedure with Quantimet (Zeiss) language and are described by Chappard. ${ }^{19}$ The trabecular bone at depth between 1 and $4 \mathrm{~mm}$ was used to calculate the histomorphometric parameters. The parameters were calculated as a function of Zoledronate content.

\section{$\mu-\mathrm{CT}$}

Twenty femurs were scanned by $\mu$-CT before preparing them for the biomechanical tests. A Scanco Medical $\mu$ CT40 scanner (Scanco Medical, Bassersdorf, Switzerland) was used at $70 \mathrm{kVp}$ with slices every $16 \mu \mathrm{m}$. $\mu$-CT data was Gauss filtered and segmented to obtain three phases: bone, marrow, and implant. Using the SCANCO software, the trabecular bone volume fraction was calculated around the implant using a concentric $500 \mu \mathrm{m}$ radius ring and centered on the cylindrical implant. The bone volume fraction was calculated as the ratio of the number of voxels belonging to the trabecular bone and the total number of voxels belonging to the total volume of the cylindrical ring (Fig. 3).

\section{Biomechanical tests}

After careful removal of all tendons and other soft tissues around the emerging part of the implant, a mold was made out of PMMA for each bone to evenly distribute the stresses and to safely pull out the implant from the condyle (Fig. 4). A tensile testing machine (Instron, Canton, USA) equipped with a $1000 \mathrm{~N}$ gauge was used. The implants were pulled with a steady speed of $1 \mathrm{~mm} / \mathrm{min}$. Displacement versus

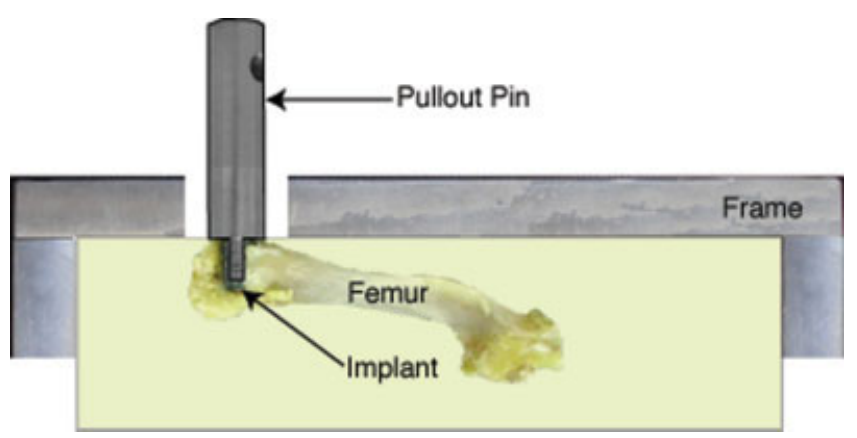

Figure 4. An individual mold was manufactured for each femur to guarantee the alignment of the implant and the pullout force. The embedded femur is placed in a steel frame. This frame is mounted onto a tensile testing machine. 
A

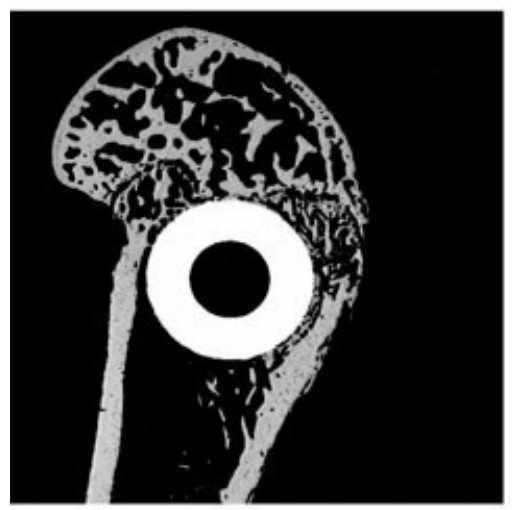

$\mathrm{C}$

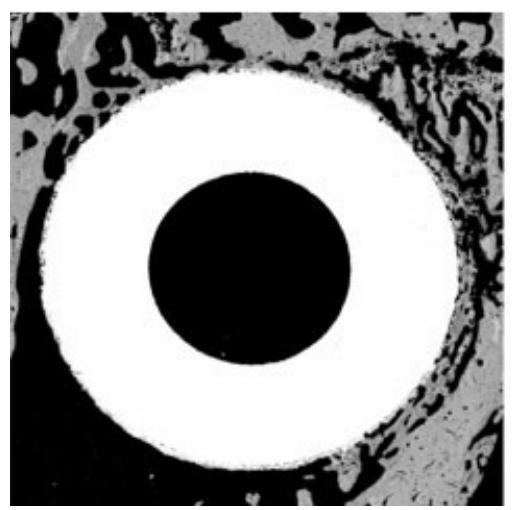

B

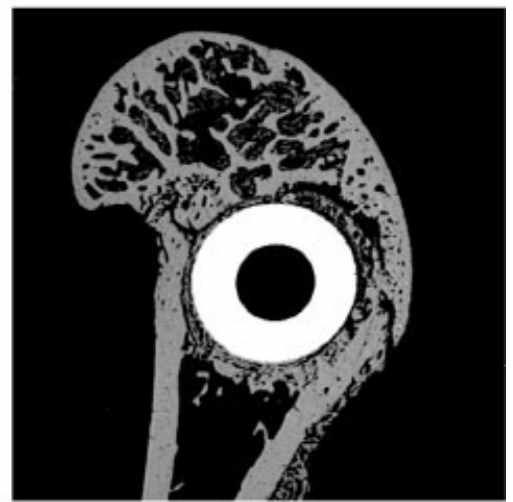

D

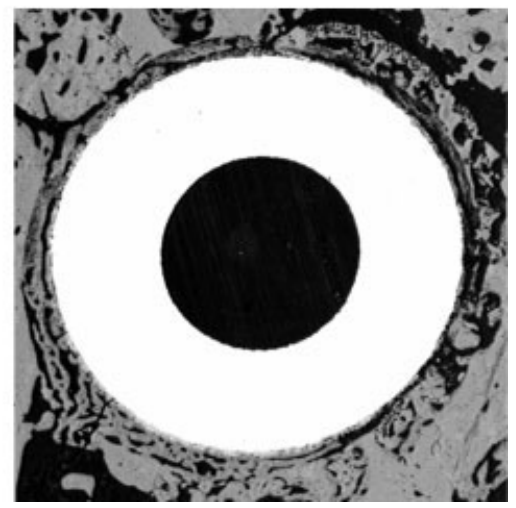

Figure 5. SEM pictures of two rat condyles at a magnification of $10 \times(A, B)$ and $23 \times(C, D)$. (A) the bone structure of a condyle implanted with an HA-coated implant containing no Zoledronate, and (B) the bone structure of the condyle containing an implant coated with HA grafted with $16 \mu \mathrm{g}$ of Zoledronate. The same implants and their peri-implant bone are shown in (C) and (D) for the coatings loaded with 0 and $16 \mu \mathrm{g}$ of Zoledronate, respectively, at a magnification of $23 \times$.

force was registered and used for the determination of the maximal pullout force.

\section{Statistics}

For the SEM, the number of slices per animal was accounted for as repetition of histomorphometric parameters and volume fraction measurement of the same animal. Oneway ANOVA and Fisher's test were used to determine the statistical significance of differences in the results. A probability value of $p=0.05$ was considered to be statistically significant.

\section{RESULTS}

\section{SEM}

The SEM pictures shown in Figure 5 clearly illustrate the positive effect of Zoledronate-coated im- plants on the peri-implant bone volume fraction in the osteoporotic rats. In the case of the coating containing no Zoledronate, the bone peri-implant volume fraction is low and the bone does not grow around the implant, whereas in the case of the implant containing $16 \mu \mathrm{g}$ of Zoledronate, the bone grows around the implant and therefore the peri-implant bone volume fraction is high.

The influence of the Zoledronate content on the bone remodeling is shown in Figure 6, where the bone volume fraction is plotted versus the distance from the implant's coating. In the first $20 \mu \mathrm{m}$, the densities around the implant loaded with any Zoledronate content are higher than the bone volume fraction around the implant without Zoledronate $(p<0.05)$. With increasing distance two groups of implants appear, which are statistically different: the first group includes the three lowest Zoledronate contents $(0,0.2$, and $2.1 \mu \mathrm{g} / \mathrm{implant})$, which decreases with the distance to the implant's surface to reach a value of 0.4 , 


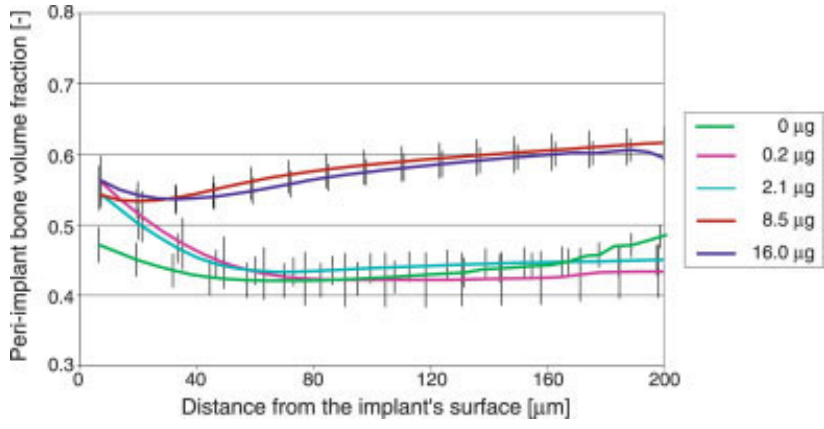

Figure 6. Bone volume fraction as function of the distance from implant surface at different Zoledronate contents. Close to the implant, all the implants containing Zoledronate lead to a high bone volume fraction. With increasing distance, the bone volume fraction decreases around the coatings containing the two lowest Zoledronate contents, while the bone volume fraction increases around the implants containing the two highest drug contents (mean \pm SEM).

while the second group (including the two highest Zoledronate doses) reached a bone volume fraction of $0.6(p<0.05)$. Only the highest Zoledronate content slightly increased the bone volume fraction at a distance of $1400 \mu \mathrm{m}$ when compared to all the other cases.

\section{Histomorphometry}

The implant coated with $0.2 \mu \mathrm{g} /$ implant significantly influenced all the histomorphometric parameters quantified $(p<0.05)$ (Fig. 7). Four parameters were increased $(\mathrm{Tm} \cdot \mathrm{Tm} / \mathrm{TSL}, \mathrm{Nd} \cdot \mathrm{Tm} / \mathrm{TSL}, \mathrm{Nd} \cdot$ $\mathrm{Nd} / \mathrm{TSL}, \mathrm{N} \cdot \mathrm{Tm}$ ) and two were decreased (TSL, Nd • Tm ratio). The total strut length (TSL) clearly demonstrated a Zoledronate content effect.

\section{$\mu-\mathrm{CT}$}

The bone volume fraction around the implant containing $0.2 \mu \mathrm{g}$ of Zoledronate is lower than when no Zoledronate is present (not significant) (Fig. 8). By further increasing the Zoledronate content of the coating, the bone volume fraction increases to reach a plateau with a coating containing $8.5 \mu \mathrm{g} /$ implant. Further increase of the Zoledronate content does not increase the bone volume fraction, but keeps it at the same value as the bone around the implant containing $8.5 \mu \mathrm{g}$ of Zoledronate. The implants containing the two highest Zoledronate contents generate bone densities which are significantly higher than the bone densities generated around the implants containing 0 and $0.2 \mu \mathrm{g}$ of Zoledronate $(p<0.05)$. In addition, the coating loaded with $2.1 \mu \mathrm{g}$ of Zoledronate generates a bone significantly denser than the bone around the implants containing $0.2 \mu \mathrm{g}(p<0.05)$.

\section{Biomechanical tests}

The maximal pullout force increased with increasing Zoledronate content up to a dose of $8.5 \mu \mathrm{g} / \mathrm{im}$ plant (Fig. 9). The maximal pullout force of the implants loaded with $16 \mu \mathrm{g}$ decreased compared to the pullout forces obtained with 2.1 and $8.5 \mu \mathrm{g} / \mathrm{implant}$ but still remained above the control. Statistically, the coating loaded with $8.5 \mu \mathrm{g}$ Zoledronate leads to an increase of the maximal pullout force compared to the pullout force obtained with the implant not containing any Zoledronate $(p<0.05)$. The other cases are statistically not different from each other.

\section{Correlations between bone volume fraction and biomechanical tests}

The correlation factors $R^{2}$ between the pullout forces and the densities taken at six distances from the implant's surface $(6,12,18,48,57$, and $200 \mu \mathrm{m})$ are shown in Figure 10. The correlation is very good for the distances of 6,12 , and $18 \mu \mathrm{m}$ with $R^{2}$ values of $0.92,0.92$, and 0.81 , respectively. With increasing distance to the implant's surface, the correlation curve drops rapidly to reach values close to zero for larger distances.

\section{DISCUSSION}

Patients with osteoporosis and joints disabilities represent a constant growing and challenging population to be treated in the musculoskeletal clinical field. Especially in the case of total hip arthroplasty, new solutions should be developed to compensate for the double negative factors, peri-implant osteolysis, and osteoporotic bone loss, affecting implants outcome. Studies over the past 2 decades have strongly implicated osteoclasts as the major cause of the bone lysis leading to implant failure. ${ }^{20}$ It has been proposed to use bisphosphonate treatment to decrease peri-implant bone lysis. ${ }^{9}$ This approach is then especially adapted for the situation involving osteoporotic patients. However, recent clinical studies have shown that systemic bisphosphonate treatment following the prosthesis implantation reduced peri-implant bone loss only after 3 months, ${ }^{11,12}$ while significant bone loss arises during this initial period of 3 months. ${ }^{14}$ Local bisphosphonate delivery may then represent an interesting approach to bring the drug immediately 
A

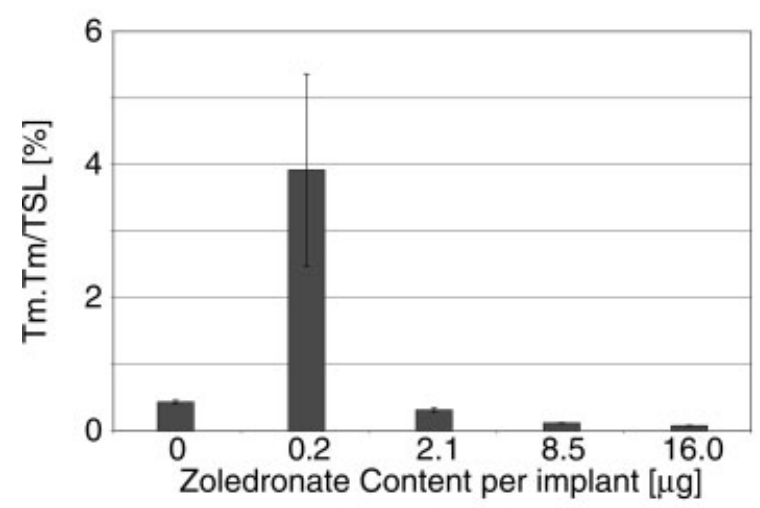

C

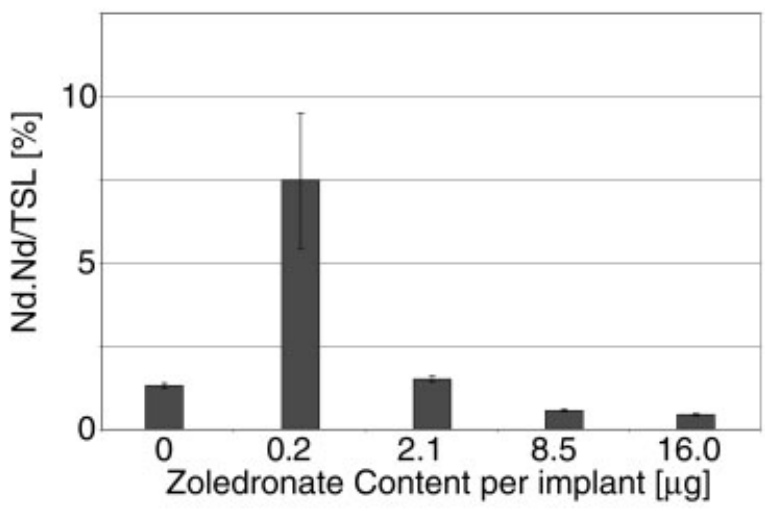

E

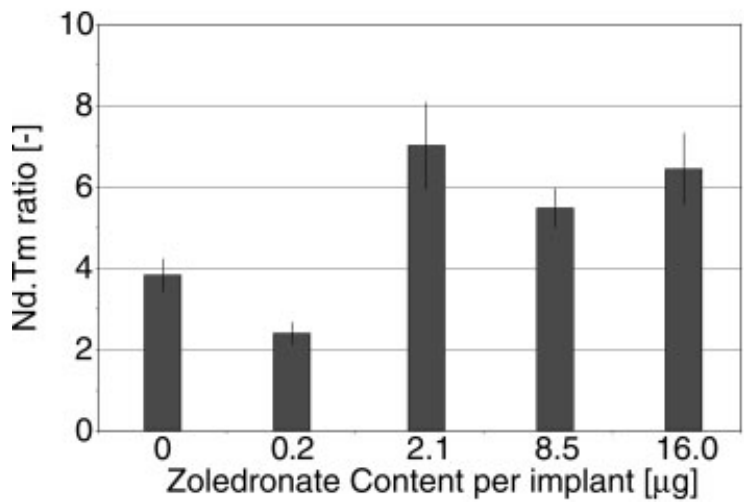

B

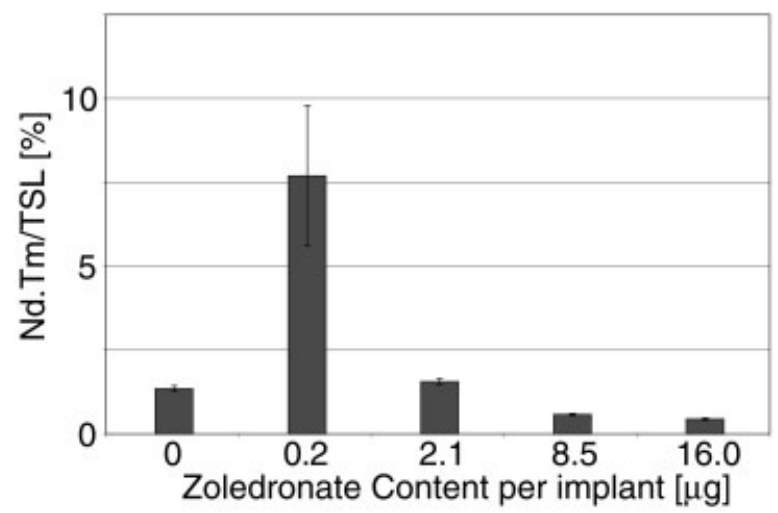

D

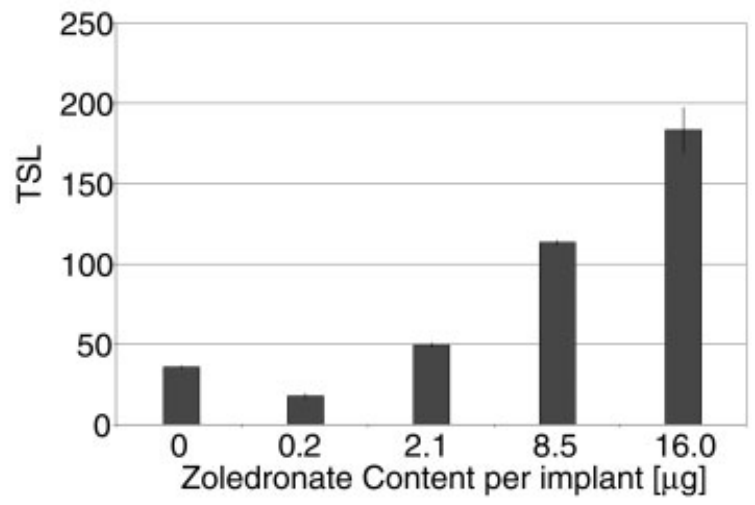

F

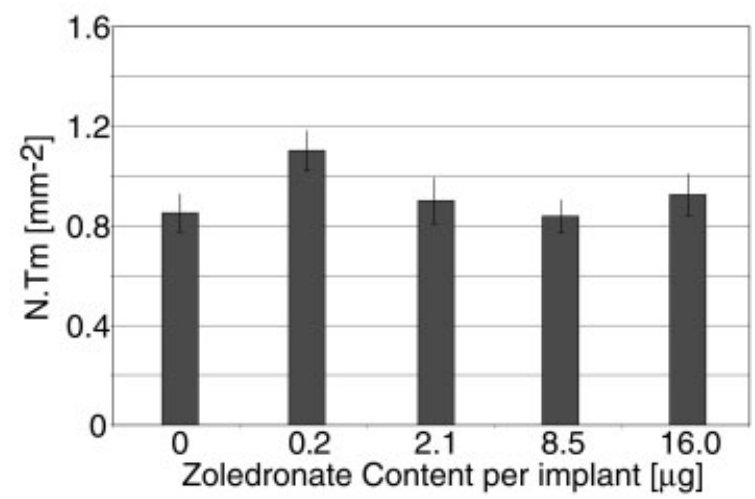

Figure 7. Histomorphometric parameters as function of the Zoledronate content (mean \pm SEM). (A) Mean length of terminus-to-terminus struts (Tm - Tm/TSL); (B) mean length of node-to-terminus struts (Nd • Tm/TSL); (C) mean length of node to node struts $(\mathrm{Nd} \cdot \mathrm{Nd} / \mathrm{TSL}) ;(\mathrm{D})$ total strut length (TSL); (E) node to termini ratio $(\mathrm{Nd} \cdot \mathrm{Tm}$ ratio); (F) number of termini in the calcified skeleton $(\mathrm{N} \cdot \mathrm{Tm})$.

into the peri-implant bone. In this study, we evaluated the possibility of using the orthopedic implants as a bisphosphonate carrier in an osteoporotic rat model.

We noted a clear positive effect on bone density and stability for the implant coated with Zoledronate. The peri-implant bone volume fraction was higher and the implant stability was increased in the treated groups. Indeed, the biomechanical pull out tests showed that the implant stability was even better than in the situ- ation with implants inserted in nonosteoporotic rat. ${ }^{16,21}$

These encouraging results have to be considered with several remarks. The study was designed to determine the Zoledronate-HA coating leading to an optimal peri-implant bone volume fraction distribution, optimal from the point of view of implant fixation. In this context, the most remarkable result was to show the existence of only one Zoledronate content 


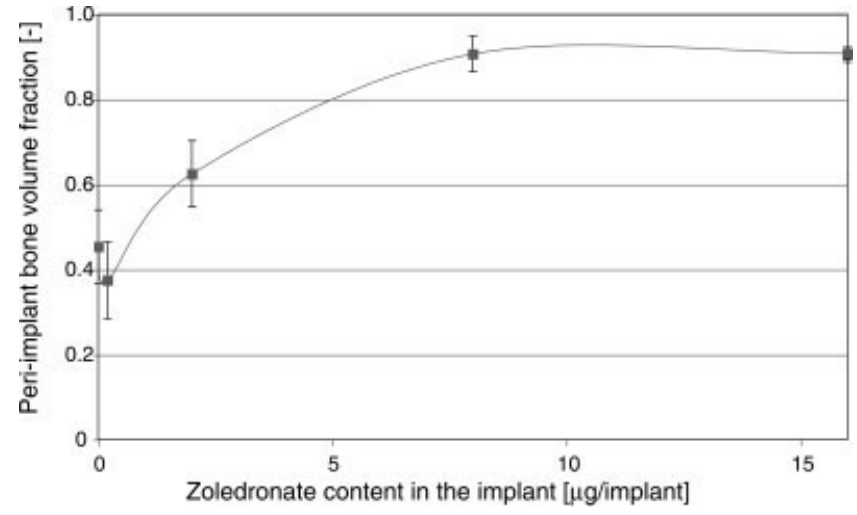

Figure 8. The bone volume fraction measured with $\mu-\mathrm{CT}$ in a $500-\mu \mathrm{m}$ radius around the implant is shown as function of the Zoledronate content of the coating. The bone volume fraction increases with increasing Zoledronate content and reaches a plateau for the two highest Zoledronate contents (mean \pm SEM).

(8.5 $\mu \mathrm{g}$ /implant) for which the mechanical fixation of the implant is increased. Translation of this Zoledronate content efficacy for clinical applications may be a nontrivial task. The in vivo model was different from the clinical situation where implants are mechanically loaded and induce micromotions at the bone-implant interface. In a recent theoretical study, we have shown that bisphosphonates may influence the bone responsiveness to mechanical stimulus. ${ }^{22}$ Indeed, the problem in peri-implant osteolysis is more with the ab-

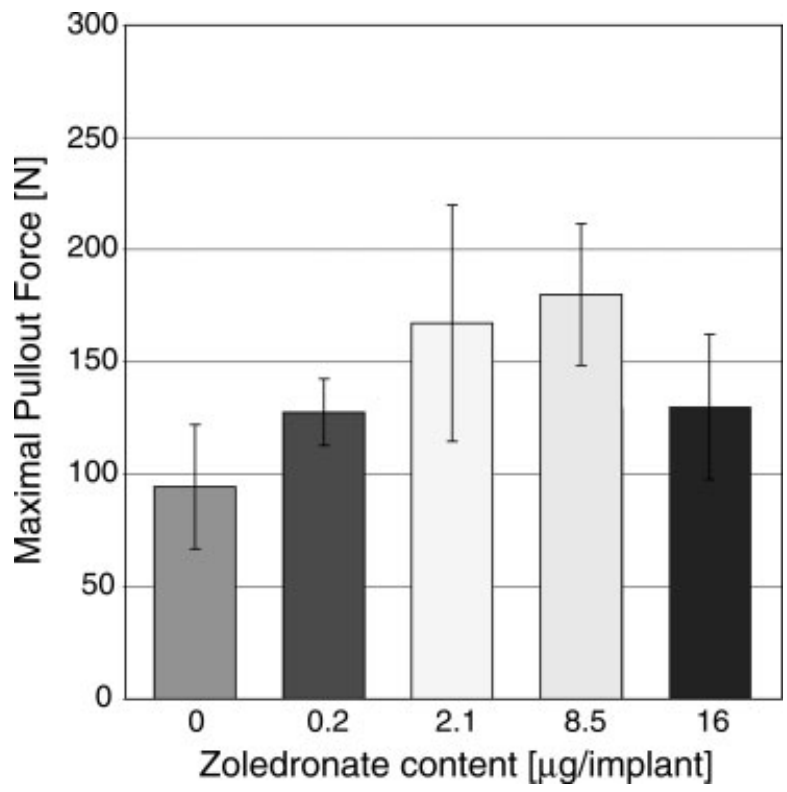

Figure 9. Pullout force as function of Zoledronate content of the coating. At low Zoledronate contents, the pullout force increases with increasing Zoledronate content of the coating. The pullout force reaches a maximum with a Zoledronate content of $8.5 \mu \mathrm{g} /$ implant. By further increasing the Zoledronate content of the coating, the pullout force decreases (mean \pm SEM).

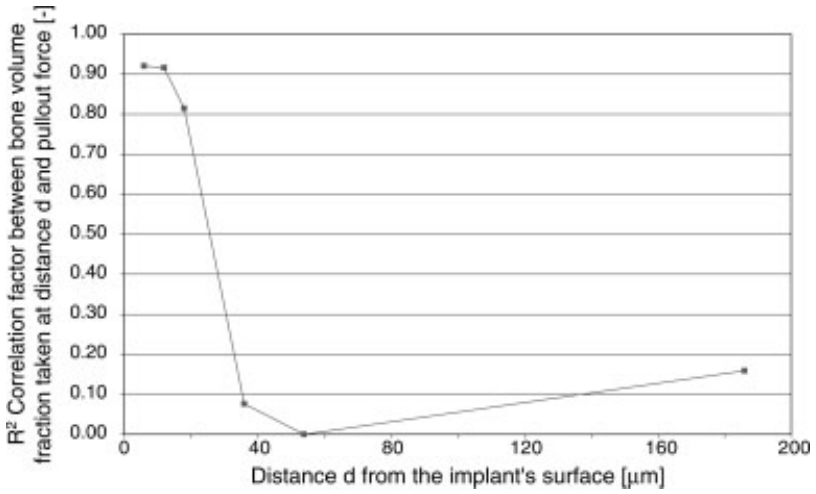

Figure 10. Correlation factor between the bone volume fraction taken at distance $d$ from the implant's surface and pullout force for osteoporotic rats.

sence of mechanical stimuli with the so-called stressshielding phenomena, ${ }^{23}$ and in this situation it has been shown that Zoledronic acid administration led to significantly greater bone area, mineral content, strength, and trabeculae number with reduced stressshielding osteopenia in a model of distraction osteogenesis. ${ }^{24}$ In a numerical study taking into account the mechanical situation, we demonstrated that the partial bisphosphonate coating of a hip implant may increase its stability. ${ }^{25}$ An in vivo model with hip implant would be helpful to confirm the positive results of local Zoledronate delivery in peri-implant bone quality.

The presented in vivo study was carried out for 3 weeks. Bisphosphonate, by affecting bone remodeling, could also block the bone repair process. The drug at too high concentrations could then have detrimental effects on the fixation of the implant over longer periods of time. Indeed, conflicting studies have reported that the use of bisphosphonate can interact with the repair of cracks and fractures, while other studies were unable to demonstrate this phenomenon. ${ }^{26,27}$ A very encouraging result was obtained in a 10-year follow up study of $10 \mathrm{mg}$ of Alendronate daily treatment, which was associated with sustained therapeutic effects on bone volume fraction and remodeling, with no indication that the antifracture efficacy of the drug was diminished. ${ }^{28}$ In addition, it has been shown that amino-bisphosphonates (like Zoledronate) do not impair with the fractures and cracks repair process due to the lower dosing. ${ }^{29}$ Long-term studies with implants used as drug delivery systems will be the next step in this development and should also show an increase in implant stability.

We checked that Zoledronate saturation in the implant coating was not achieved. ${ }^{17}$ Basically, we have demonstrated that there are two modes of association between calcium phosphates (including HA) and Zoledronate. ${ }^{18}$ The first mode is chemisorption (via PO3-PO4 exchange), and when saturation is achieved, 
the formation of a crystalline compound, probably a calcium salt of zoledronic acid, occurs at the surface of the material. This crystalline compound can easily be detected by NMR and SEM. As uncemented orthopedic implants are usually coated with HA, the combination of HA and Zoledronate is then an easy transformation of currently adopted standard in the orthopedic field.

The measurements with the $\mu$-CT were performed to quantify the bone volume fraction around the implants before subjecting them to the pullout tests. Moreover, the contact surface between the bone and the implant should have been measured to verify if the presence of Zoledronate had an influence on the failure stress. Due to the interaction between the metallic implant and the X-rays used in the $\mu$-CT, the resolution close to the implant was low, which prevented the calculations of peri-implant bone contact surface with sufficient precision. However, the bone volume fraction measurements along the long axis confirm the Zoledronate dose effect on the bone volume fraction.

In most in vivo studies, the effect of bisphosphonates on the histomorphometry of bone was an increase in trabecular number and thickness and a decrease of trabecular separation. ${ }^{24,30,31}$ In our study, none of those parameters seem to be altered by the presence of Zoledronate. These differences may be due to the fact that in the other studies, the bisphosphonate passed through the gastrointestinal apparatus and the blood stream before reaching the bone, while in our case, the bisphosphonate was directly put into contact with the bone through the means of the HA coating. The delivery type would probably influence the bioavailability and the distribution of bisphosphonate in the bone, and thus the peri-implant bone volume fraction and morphology.

To control the bone remodeling around implant, pharmacological treatment of peri-implant osteolysis has been proposed with TNF antagonist systemic treatment but without clear positive effects observed. ${ }^{32}$ An indirect way of evaluating the effect of Alendronate treatment on orthopedic implants outcome has been performed in the canine model using an implantable bone growth chamber. ${ }^{33}$ Alendronate did not affect bone integration. The background of this study was related to the fact that patients at high risk for osteoporosis are currently treated with bisphosphonate, as it has been shown that osteoporosis does not protect against the development of coxarthrosis. ${ }^{34}$ Beside Alendronate, different bisphosphonates have been tested for decreasing peri-implant osteolysis. Iwase et al. ${ }^{35}$ used a novel bisphosphonate (TRK-530) with inhibitor effects on osteoclast formation and TNF expression. They showed a decreased osteolysis in the rat osteolysis model with continuous infusion of particles. The bisphosphonate was injected with the particles making the model not clinically relevant. Despite systemic bisphosphonates, treatment seems to successfully increase bone mineral density and to prevent bone fracture in general, a careful analysis of the existing literature highlights that differences between skeletal sites are present. A phase III Alendronate clinical trial showed that daily treatment of Alendronate in 994 women for 3 years had a more potent effect on bone mineral density in the spine than in the proximal femur. ${ }^{36}$ The actual systemic bisphosphonates delivery seems then to be inefficient to target proximal femoral bone. This might explain the apparent inefficiency of systemic bisphsophonate treatment to reduce the peri-implant osteolysis during the first 3 months following the beginning of the treatment. ${ }^{11,12}$ Another major disadvantage of the clinically utilized bisphosphonates is their poor oral absorption from the gastrointestinal tract, typically less than $1 \%$ is absorbed. ${ }^{37}$ All these drawbacks (low bisphosphonates uptake especially at the proximal femur site, no optimal administration route, low patient compliance) with the use of the bisphosphonates advocate for further developments in the administration route. As for other pharmacological treatments, the drug delivery system may present an important beneficial potential.

Several studies have been recently performed to combine implant and bisphosphonate. Tengvall ${ }^{38}$ showed an increase by $28 \%$ of the pullout force of steel screws inserted in rat femurs by using a fibrinogen/pamidronate/ibandronate coating. In a study performed with nonosteoporotic rats, ${ }^{16}$ the implants containing $2.1 \mu \mathrm{g}$ of Zoledronate induced an increase in pullout force up to $42 \%$ compared to implants without Zoledronate. The combination of HA and Zoledronate is probably more favorable than fibrinogen and bisphosphonate in the point of view of orthopedic implant fixation. Using a coating of Pamidronate, implants inserted in immature rats stimulated new bone formation around the implant, suggesting a supportive osteointegration effect for bisphosphonate. ${ }^{15}$ No information on implant stability and quantity of bisphosphonate coated was given.

In the present study, the amount of Zoledronate coated on the implant was precisely determined, allowing evaluation of its dose effect on the peri-implant bone. The coating containing $8.5 \mu \mathrm{g}$ of Zoledronate per implant induced the highest implant mechanical stability, a key property for the long-term implant survival. The correlation between bone volume fraction and mechanical stability showed that the first 20 $\mu \mathrm{m}$ are of uttermost importance for the mechanical fixation of an implant. Therefore, the approach of increasing the peri-implant volume fraction by a local drug delivery becomes even more justified. 


\section{CONCLUSION}

In conclusion, this study was able to establish the proof of concept for orthopedic implants used as a drug delivery system in osteoporotic rats. The local bisphosphonate delivery from a calcium phosphate coating allowed to increase the mechanical fixation of an orthopedic implant. Moreover, we showed that the increase in peri-implant bone volume fraction is dependent on the Zoledronate content of the coating. The mechanical stability of an implant is correlated to the bone volume fraction in the $20 \mu \mathrm{m}$ of bone around the implant advocating for a local delivery of the bisphosphonate. Orthopedic implant as bisphosphonate delivery may then represent an interesting approach for osteoporotic patients in need of a total joint replacement.

We thank Novartis Pharma Research (Basel) for a generous gift of Zoledronate and J.R. Green (Novartis Pharma Research) for fruitful discussion. We thank Paul Pilet for technical assistance.

\section{References}

1. Schmidt AH, Swiontkowski MF. Femoral neck fractures. Orthop Clin North Am 2002;33:97-111.

2. Kirsh G, Roffman M, Kligman M. Hydroxyapatite-coated total hip replacements in patients 65 years of age and over. Bull Hosp Jt Dis 2001;60:5-9.

3. Moreland JR, Moreno MA. Cementless femoral revision arthroplasty of the hip: Minimum 5 years followup. Clin Orthop 2001;393:194-201.

4. Kligman M, Kirsh G. Hydroxyapatite-coated total hip arthroplasty in osteoporotic patients. Bull Hosp Jt Dis 2000;59:136139.

5. Jaffe WL, Scott DF. Total hip arthroplasty with hydroxyapatitecoated prostheses. J Bone Joint Surg Am 1996;78:1918-1934.

6. Mjoberg B. The theory of early loosening of hip prostheses. Orthopedics 1997;20:1169-1175.

7. Epinette JA, Manley MT. Fifteen years of clinical experience with hydroxyapaptite coating in joint arthroplasty. Paris: Springer; 2004

8. Herberts P, Malchau H, Garellick G. The Swedish National Hip Arthroplasty Register. Annual report 2002; 2003.

9. Shanbhag AS, Hasselman CT, Rubash HE. The John Charnley Award. Inhibition of wear debris mediated osteolysis in a canine total hip arthroplasty model. Clin Orthop 1997;344:3343.

10. Goodman SB, Huie P, Song Y, Lee K, Doshi A, Rushdieh B, Woolson S, Maloney W, Schurman D, Sibley R. Loosening and osteolysis of cemented joint arthroplasties. A biologic spectrum. Clin Orthop 1997;337:149-163.

11. Venesmaa PK, Kroger HP, Miettinen HJ, Jurvelin JS, Suomalainen OT, Alhav EM. Alendronate reduces periprosthetic bone loss after uncemented primary total hip arthroplasty: A prospective randomized study. J Bone Miner Res 2001;16:2126-2131.

12. Nehme A, Maalouf G, Tricoire JL, Giordano G, Chiron P, Puget $\mathrm{J}$. Effect of alendronate on periprosthetic bone loss after cemented primary total hip arthroplasty: A prospective random- ized study. Rev Chir Orthop Reparatrice Appar Mot 2003;89: 593-598.

13. Yamaguchi K, Masuhara K, Yamasaki S, Nakai T, Fuji T. Cyclic therapy with etidronate has a therapeutic effect against local osteoporosis after cementless total hip arthroplasty. Bone 2003 33:144-149.

14. Venesmaa PK, Kroger HP, Miettinen HJ, Jurvelin JS, Suomalainen OT, Alhava EM. Monitoring of periprosthetic BMD after uncemented total hip arthroplasty with dual-energy X-ray absorptiometry-A 3-year follow-up study. J Bone Miner Res 2001;16:1056-1061.

15. Kajiwara H, Yamaza T, Yoshinari M, Goto T, Iyama S, Atsuta I, Kido MA, Tanaka T. The bisphosphonate pamidronate on the surface of titanium stimulates bone formation around tibial implants in rats. Biomaterials 2005;26:581-597.

16. Peter B, Pioletti DP, Laib S, Bujoli B, Pilet $\mathrm{P}$, Janiver $\mathrm{P}$ Guicheux J, Zambelli P-Y, Bouler J-M, Gauthier O. Calcium phosphate drug delivery system: Influence of local zoledronate release on bone implant osteointegration. Bone 2004; 36:52-60.

17. Josse S, Faucheux C, Soueidan A, Grimandi G, Massiot D, Alonso B, Janvier P, Laïb S, Pilet P, Gauthier O, Daculsi G, Guicheux J, Bujoli B, Bouler J-M. Novel biomaterials for bisphosphonate delivery. Biomaterials 2005;26:2073-2080.

18. Josse S, Faucheux C, Soueidan A, Grimandi G, Massiot D, Alonso A, Janvier P, Laïb S, Gauthier O, Daculsi G, Guicheux J, Bujoli B, Bouler J-M. Chemically modified calcium phosphates as biomaterials for drug delivery. Adv Mater 2004;16: 1423-1427.

19. Chappard D, Legrand E, Pascaretti C, Basle MF, Audran M. Comparison of eight histomorphometric methods for measuring trabecular bone architecture by image analysis on histological sections. Microsc Res Tech 1999;45:303-312.

20. Haynes DR, Crotti TN, Zreiqat H. Regulation of osteoclast activity in peri-implant tissues. Biomaterials 2004;25:48774885.

21. Peter B. Orthopedic implants used as drug delivery systems: numerical, in vitro and in vivo studies [PhD]. Lausanne: Swiss Federal Institute of Technology-Lausanne; 2004.

22. Pioletti DP, Rakotomanana LR. Can the increase of bone mineral density following bisphosphonates treatments be explained by biomechanical considerations? Clin Biomech 2004; 19:170-174.

23. Van Rietbergen B, Huiskes R, Weinans H, Sumner DR, Turner TM, Galante JO. ESB Research Award 1992. The mechanism of bone remodeling and resorption around press-fitted THA stems. J Biomech 1993;26:369-382.

24. Little DG, Smith NC, Williams PR, Briody JN, Bilston LE, Smith EJ, Gardiner EM, Cowell CT. Zoledronic acid prevents osteopenia and increases bone strength in a rabbit model of distraction osteogenesis. J Bone Miner Res 2003;18:13001307.

25. Peter B, Ramaniraka N, Rakotomanana LR, Zambelli PY, Pioletti DP. Peri-implant bone remodeling after total hip replacement combined with systemic alendronate treatment: A finite element analysis. Comput Methods Biomech Biomed Engin 2004;7:73-78.

26. Li J, Mashiba T, Burr DB. Bisphosphonate treatment suppresses not only stochastic remodeling but also the targeted repair of microdamage. Calcif Tissue Int 2001;69:281-286.

27. Li J, Mori S, Kaji Y, Kawanishi J, Akiyama T, Norimatsu H. Concentration of bisphosphonate (incadronate) in callus area and its effects on fracture healing in rats. J Bone Miner Res 2000;15:2042-2051.

28. Bone HG, Hosking D, Devogelaer JP, Tucci JR, Emkey RD, Tonino RP, Rodriguez-Portales JA, Downs RW, Gupta J, Santora AC, Sautona AC, Liberman UA. Ten years' experience 
with alendronate for osteoporosis in postmenopausal women. N Engl J Med 2004;350:1189-1199.

29. Bartl R, Frisch B. Das Bisphosphonat-Manual. Berlin; Blackwell-Science 2001.

30. Motoie H, Nakamura T, O'Uchi N, Nishikawa H, Kanoh H, Abe T, Kawashima H. Effects of the bisphosphonate YM175 on bone mineral density, strength, structure, and turnover in ovariectomized beagles on concomitant dietary calcium restriction. J Bone Miner Res 1995;10:910-920.

31. Sato M, Vahle J, Schmidt A, Westmore M, Smith S, Rowley E, Ma LY. Abnormal bone architecture and biomechanical properties with near-lifetime treatment of rats with PTH. Endocrinology 2002;143:3230-3242.

32. Schwarz EM, Campbell D, Totterman S, Boyd A, O'Keefe RJ, Looney RJ. Use of volumetric computerized tomography as a primary outcome measure to evaluate drug efficacy in the prevention of peri-prosthetic osteolysis: A 1-year clinical pilot of etanercept vs. placebo. J Orthop Res 2003;21:10491055.

33. Frenkel SR, Jaffe WL, Valle CD, Jazrawi L, Maurer S, Baitner A, Wright K, Sala D, Hawkins M, Di Cesare PE. The effect of alendronate (Fosamax) and implant surface on bone integra- tion and remodeling in a canine model. J Biomed Mater Res 2001;58:645-650.

34. Healey JH, Vigorita VJ, Lane JM. The coexistence and characteristics of osteoarthritis and osteoporosis. J Bone Joint Surg Am 1985;67:586-592.

35. Iwase M, Kim KJ, Kobayashi $\mathrm{Y}$, Itoh M, Itoh T. A novel bisphosphonate inhibits inflammatory bone resorption in a rat osteolysis model with continuous infusion of polyethylene particles. J Orthop Res 2002;20:499-505.

36. Liberman UA, Weiss SR, Broll J, Minne HW, Quan H, Bell NH, Rodriguez-Portales J, Downs RW Jr, Dequeker J, Favus M. Effect of oral alendronate on bone mineral density and the incidence of fractures in postmenopausal osteoporosis. The Alendronate Phase III Osteoporosis Treatment Study Group. N Engl J Med 1995;333:1437-1443.

37. Ezra A, Golomb G. Administration routes and delivery systems of bisphosphonates for the treatment of bone resorption. Adv Drug Deliv Rev 2000;42:175-195.

38. Tengvall P, Skoglund B, Askendal A, Aspenberg P. Surface immobilized bisphosphonate improves stainless-steel screw fixation in rats. Biomaterials 2004;25:2133-2138. 